\title{
AS LEIS DISCRIMINATÓRIAS DE ISRAEL À LUZ DO DIREITO \\ INTERNACIONAL
}

Julia Caligiorne Santos ${ }^{1}$

\begin{abstract}
Resumo:
Desde a criação do Direito Internacional até a instituição das normas de jus cogens, consideráveis evoluções têm sido observadas nas lógicas de poder no âmbito jurídico internacional. 0 presente resumo de pesquisa procurará elucidar, em um primeiro momento, os fundamentos primevos e atuais do Direito Internacional, no que tange à relação norma interna versus norma internacional. Para ilustrar as teorias, traz-se o exemplo do Estado de Israel e o rol de leis discriminatórias presentes em sua constituição, mesmo o tal sendo signatários de numerosas convenções internacionais de proteção racial.
\end{abstract}

Palavras chaves: Direito Internacional. Estado de Israel. Leis Discriminatórias.

\section{Abstract:}

From the creation of international law to the imposition of jus cogens norms, considerable developments have been observed in the logics of power in the international legal framework. This research summary seeks to elucidate at first the primeval and current fundamentals of international law, with respect to internal norm versus international norm conflict. To illustrate the theories, the paper bring the example of the State of Israel and the role of discriminatory laws present in its constitution, even if the State has being signatory of numerous international conventions of racial protection.

Keywords: International Law. State of Israel. Discriminatory laws.

\section{Introdução}

O direito internacional tem regulamentado as relações entre os Estados (ou Nações, povos) desde os primeiros indícios de sua existência na Antiguidade, através de práticas comerciais e diplomáticas, até os dias atuais. Logo após a Paz de Vestfália, em 1648, houve grande reformulação do conceito, que passou a considerar o Estado-nação como fonte e sujeito primordial da ordem pública internacional. Desde então o conceito apenas tem crescido e granjeado novas conotações, assim como ampliado seu destaque no seio das dinâmicas políticas internacionais.

\footnotetext{
1 Pós-graduanda em Direito Internacional pelo Centro de Direito Internacional de Belo Horizonte (Cedin) e Bacharel em Relações Internacionais pela PUC Minas. Estagiou no departamento de Advocacia Internacional do Centro Legal para os Direitos da Minoria Árabe em Israel, que tornou possível o desenvolvimento da pesquisa, a qual diz respeito este resumo.
} 
Com o aparecimento gradativo dos tratados internacionais sobre direitos humanos e a estabelecimento das normas de jus cogens, as influências positivas e negativas do direito internacional na política têm ganhado contornos bem delineados: o peso moral do não cumprimento e da não convenção tem sido cada vez maior, por mais que as consequências ainda permaneçam no nível abstrato.

O Estado de Israel, desde sua criação em 1948, tem aderido a importantes convenções internacionais, inclusive de direitos humanos dos direitos das minorias étnicas. Tal adesão, mesmo que provocada por interesses políticos, não excluí a sua obrigatoriedade e, portanto, sua responsabilidade para com o que foi acordado. Curiosamente, na sua legislação interna, o Estado possui um rol de leis discriminatórias que vão absolutamente contra normas pactuadas externamente. Leis fundamentais, na visão de convenções tão importantes como a ICERD (International Convention on the Elimination of All Forms of Racial Discrimination), da qual Israel é um signatário.

Por conseguinte, esta pesquisa abordará, em um primeiro momento, preceitos básicos sobre os fundamentos e objetivos do direito internacional como órgão regulador do sistema de Estados. Posteriormente, discorrerá sobre a contradição das normas internacionais pactuadas e as normas internas do Estado de Israel, através de breves exemplos de legislações aplicáveis.

\section{Os Princípios do Direito Internacional}

"Entre fortes e fracos, a liberdade oprime e o direito liberta" Padre Henri Lacordaire

A fundação do Direito Internacional pode ser ilustrada de óticas distintas, porém é frequentemente visualizada sob a vertente da racionalidade instrumental, que procura abarcar sua natureza e seus objetivos. Logo, a origem de ordem jurídica internacional é historicamente entendida como consequência da necessidade de manter o status quo e o equilíbrio entre as nações, buscando a cooperação no âmbito universal. Ou seja, o objetivo inicial da criação do direito internacional é puramente racional, com pouca ou nula atenção à promoção de desenvolvimento e preservação da vida humana. A utilização de normas internacionais pré-acordadas serviria principalmente como um 
curso de ação propício devido ao menor custo-benefício. Inúmeros pensadores apontam as raízes da necessidade de cooperação como sendo a partir da Primeira Guerra Mundial: com a invenção da metralhadora e outros avanços bélicos consideráveis, a guerra passou a não mais 'compensar' racionalmente (pois se tornou dispendiosa) levando a criação de outros meios menos onerosos, como a criação de instituições que regulassem as relações entre as nações. Entretanto, como pontua Accioly (2009), devido ao princípio da soberania, o Estado encontra-se acima dos demais sujeitos de direito, constituindo autoridade máxima em seu território. Externamente, porém, o Estado está em pé de igualdade com os demais Estados soberanos que compõem a sociedade internacional.

Desta forma, sendo o direito internacional um conjunto de normas coesas que busca regulamentar as interações entre os Estados soberanos, existem alguns elementos básicos que devem ser considerados para a sua concepção. A sociedade internacional, contrariamente às sociedades nacionais organizadas em Estados, é descentralizada, ou seja, não há um órgão central produtor das regras a serem dirigidas e vincularem, de modo geral, os sujeitos de direito internacional. Outra característica é a de que, pelos Estados serem considerados juridicamente iguais, e, portanto não existir uma entidade superior que tenha o poder de impor o cumprimento da ordem jurídica internacional, a relação neste âmbito é de coordenação (ao contrário do que é observado no direito interno, em que a relação é de subordinação). E, justamente por não possuir órgão central e superior dotado de prerrogativas, os Estados são os próprios autores e destinatários das normas internacionais. A lógica principal do direito internacional repousa-se sobre o consentimento, tradicionalmente expresso no princípio pacta sunt servanda ${ }^{2}$, em que um Estado é obrigado no plano internacional apenas na medida em que consentir a vincular-se juridicamente. (REZEK, 2011)

A relação entre direito internacional e direito interno, um dos focos estruturais deste trabalho, é entendida por pensadores de algumas formas distintas. A teoria dualista, que possui em sua formulação autores de destaque como Triepel e Anzilotti,

\footnotetext{
${ }^{2}$ Pacta sunt servanda - o princípio segundo o qual o que foi pactuado deve ser cumprido - é um modelo de norma fundada no consentimento perceptivo. Regras resultantes do consentimento criativo são aquelas das quais a comunidade internacional poderia prescindir. São aquelas que evoluíram em determinado sentindo, quando perfeitamente poderiam ter assumido sentido diverso, ou mesmo contrário. E é impossível, em definitivo, conceber que a mais rudimentar das comunidades sobreviva sem que seus integrantes reconheçam, quando menos, o dever de honrar as obrigações livremente assumidas. (REZEK, Direito Internacional Público: curso elementar. 2011, p. 27)
} 
pontua que o direito internacional e direito interno de cada Estado são dois sistemas rigorosamente independentes, de modo que a validade jurídica de uma norma interna não se condiciona à sua sintonia com a ordem internacional. (REZEK, 2011)

Dentro da lógica dualista, para que uma norma de direito internacional seja aplicada na ordem interna de um Estado, primeiramente deve-se transformá-la em norma de direito interno, incorporando-a ao seu ordenamento jurídico doméstico. Também chamada de teoria da incorporação, a doutrina diz que não existiria a possibilidade de conflito entre as duas ordens jurídicas, por serem completamente independentes. (Accioly. Tratado de Direito Internacional Público. 2009)

Os autores monistas se divergem em duas correntes distintas: a primeira sustenta a unicidade jurídica sob o primado do direito internacional, a que se ajustariam todas as ordens internas, também denominado monismo com supremacia do direito internacional.

Formulada por Hans Kelsen, Alfred Verdross, Léon Duguit e outros, a doutrina do monismo com supremacia do direito internacional não consente a existência de duas ordens jurídicas independentes, alegando haver apenas um único ordenamento jurídico, no qual o direito internacional é considerado superior ao direito interno. Baseando-se na pirâmide normativa kelseniana, os proponentes entendem que a norma fundamental (no vértice da pirâmide) seria uma regra de Direito Internacional, pacta sunt servanda, da qual derivariam sua validade as demais. Segundo os seus defensores, não seria possível o conflito entre o direito internacional e o direito interno, pois prevaleceria a norma hierarquicamente superior. (Accioly. Tratado de Direito Internacional Público. 2009)

A outra vertente, o monismo com supremacia do direito interno, apregoa o primado do direito nacional de cada Estado soberano, sob cuja ótica a adoção de preceitos do direito internacional aparece como uma faculdade arbitrária. (REZEK, 2011)

\begin{abstract}
Com raízes no hegelianismo, a doutrina defende que o Estado é dotado de soberania absoluta e que, portanto, somente se sujeita a um sistema jurídico que emane de si próprio. Desta forma, o direito internacional derivaria sua obrigatoriedade do direito interno, e o fundamento daquele seria apenas a autolimitação do Estado. Esta teoria enxerga a existência de uma exclusiva ordem jurídica, mas identifica-a com a interna - o direito internacional seria simplesmente a continuação do direito interno, aplicado às relações exteriores do Estado. Esposaram esta doutrina Georg Jellinek, Georges Burdeau e os juristas soviéticos. (Accioly. Tratado de Direito Internacional Público. 2009)
\end{abstract}

Nenhuma das três proposições são invulneráveis às críticas, contudo, cada uma pode ser valorizada com mérito para explicar a constante dicotomia, existente ainda hoje, de ambos cenários jurídicos. (REZEK, 2011)

Se o direito internacional foi visto, e ainda o é, como um instrumento de otimização dos ganhos individuais dos Estados através da prevenção da guerra, pode-se 
dizer que atualmente é possível falar de outros benefícios para a adesão à ordem jurídica internacional. A crescente normatização das ações politicamente aceitas e a imperatividade das normas de jus cogens, trouxeram ao Estado um peso moral para as suas ações unilaterais que vão contra normas internacionalmente construídas. Desta forma, não cooperar ou não aderir aos tratados internacionais tornou-se um custo extra a ser analisado pelo Estado, quando da aplicação de sua política externa. Outros, porém, apontam tal ênfase do direito internacional na política contemporânea como mais um meio eficaz de controle, por parte dos sujeitos internacionais influentes, da sociedade internacional.

Sejam quais for as razões que fundamentam a adesão dos Estados às fontes de direito internacional, uma vez realizado o pacto, o Estado está sujeito à Responsabilidade Internacional, que configura "responsabilidade pela prática de um ato ilícito segundo o direito internacional, devendo arcar com as reparações adequadas" (REZEK, 2011). Não há escusa para o ato internacionalmente ilícito no argumento de sua licitude ante a ordem jurídica local, uma vez que a norma foi pactuada em algum fórum internacional. A punição para tal penalidade, assim como as demais punições, ainda é bastante abstrata, e talvez seja essa a grande dificuldade do direito internacional. Pelo direito e política internacional estarem intimamente atrelados, a aplicabilidade do primeiro torna-se quase que condicional ao segundo. Todavia, já se pode falar de constrangimento internacional e certo grau de deslegitimação política dos sujeitos que infringem as normas das quais são signatários, afinal, procura-se ainda acreditar na importância do direito internacional como plataforma primordial para estabelecimento da paz, igualdade e justiça mundial, e seus adeptos como sujeitos empenhados na perpetuação de tais valores.

The objectives of international law appear differently depending on one's standpoint. International law certainly seeks to realize the political values, interests, and preferences of various international actors. But it also appears as a standard of criticism and means of controlling those in powerful positions. Beyond pointing to the oscillation between instrumentalism and formalism as styles of legal thought and practice, however, the question 'what is international law for?' also invokes popular aspirations about peace, justice, and human rights, and thus acts as a platform for an international political community. Whatever its shortcomings, international law also exists as a promise of justice, and thus as encouragement for political transformation. (KOSKENNIEMI, What is International Law for? p.89) 


\section{Leis Internacionais de Proteção Racial versus Leis Domésticas Discriminatórias do Estado de Israel}

O Estado de Israel, apesar de ser um Estado democrático de facto, possui uma constituição repleta de leis discriminatórias à etnia árabe, com o intuito de desmoralizar a densa parcela de cidadãos palestinos habitantes do seu território.

Cidadãos palestinos de Israel são os palestinos que ficaram para trás no que se tornou o Estado de Israel após a Nakba (1947-9), ou "catástrofe palestina", quando cerca de 750 mil palestinos foram expulsos de suas casas e terras pelas forças sionistas, a fim de abrir caminho para um Estado judeu de maioria ${ }^{3}$.

Desigualdade em Israel assume muitas formas. Algumas das principais linhas divisórias da sociedade israelense, criando grupos relativamente privilegiados e privados, são Asquenazim versus Mizrahim4; homens versus mulheres; judeus nascidos em Israel (Sabar) versus os novos imigrantes (Olim); judeus ortodoxos versus judeus seculares; moradores rurais versus moradores urbanos; ricos versus pobres; partidários de esquerda versus partidários de direita; e homossexuais versus heterossexuais. Neste trabalho abranger-se-á as desigualdades entre os cidadãos judeus de Israel - a maioria e os cidadãos árabe-palestinos de Israel, uma minoria nacional, não imigrante, vivendo em sua pátria histórica. (ADALAH, 2011)

Entre 1948 (quando Israel declarou a independência) e 1966, os palestinos que viviam em Israel foram banidos de quaisquer direitos políticos e estavam sujeitos ao regime militar israelense. Depois de 1966, foram concedidos o direito de voto e outros direitos civis, mas até hoje eles continuam a sofrer de discriminação generalizada, sistemática e institucionalizada que afeta tudo, desde a propriedade da terra e as oportunidades de emprego até os direitos de unificação familiar. Hoje, existem cerca de 1,2 milhões de cidadãos palestinos de Israel, cerca de $20 \%$ da população ${ }^{5}$. Eles permaneceram em sua terra natal, após a criação do Estado de Israel em 1948,

\footnotetext{
3 Dados de 2011, retirados do portal virtual do IMEU - Institute for Middle East Understanding, contemplado na bibliografia.

${ }^{4}$ Asquenazim é o nome dado aos judeus provenientes da Europa Central e Europa Oriental. 0 termo provém do termo do hebraico medieval para a Alemanha, chamada Ashkenaz (אשכנז). Os judeus mizrahim são aqueles originários das comunidades do Oriente Médio. Geralmente o termo se aplica aos judeus que vivem ou viveram no mundo islâmico. Trata-se de comunidades fortemente arabizadas nas suas tradições linguísticas, alimentares e culturais. (Dados retirados da Wikipedia.org, acesso em 22 de Maio de 2014).

5 Dados de 2011, retirados do portal virtual do IMEU - Institute for Middle East Understanding, contemplado na bibliografia.
} 
tornando-se uma minoria involuntária. Uma parte do povo palestino, que atualmente vive na Cisjordânia, na Faixa de Gaza e os refugiados, pertencem a três principais comunidades religiosas: muçulmana (82\%), cristã $(9,5 \%)$ e drusa $(8,5 \%)^{6}$.

O seu status no âmbito dos instrumentos internacionais de direitos humanos dos quais Israel é um Estado parte, é a de uma minoria nacional, étnica, linguística e religiosa. No entanto, apesar desse status, a minoria palestina não é declarada como uma minoria nacional nas Leis Básicas de Israel. Em 1948, Israel foi estabelecido como um Estado judeu e a definição de Israel como "Estado judeu" ou "o Estado do povo judeu" apresenta na prática a desigualdade como uma realidade política e ideológica para os cidadãos palestinos do mesmo, que são marginalizados e discriminados com base na sua pertença nacional e filiação religiosa como "Não-judeus". (ADALAH, 2011) Além disso, essa percepção não se restringe às autoridades estaduais: de acordo com o Instituto de Democracia de Israel, em 2010, 53\% do público judeu defendeu que o estado tinha direito a encorajar os árabes a emigrar de Israel ${ }^{7}$. De acordo com uma pesquisa recente retirada do relatório anual da Adalah ${ }^{8}$, uma organização não governamental que defende os direitos da minoria árabe dentro de Israel, apenas 51\% dos judeus cidadãos de Israel apoiam a plena igualdade de direitos entre os cidadãos judeus e árabes no país. A mesma atitude prevalece entre os jovens judeus, com 49,5\% dos judeus de 15 a 18 anos respondendo negativamente, em uma pesquisa realizada em $2010^{9}$, à questão de saber se aos cidadãos árabes deveriam ser concedidos direitos iguais aos dos judeus.

Numerosos grupos de cidadãos palestinos de Israel enfrentam "discriminação composta" ou múltiplas formas de discriminação com base tanto na sua pertença nacional quanto na sua participação em um ou mais subgrupos distintos. Por exemplo, as mulheres árabes em Israel sofrem discriminação, como membros da minoria árabe e como mulheres, e os árabes beduínos enfrentam uma camada adicional de discriminação institucional e social. No que diz respeito a certos grupos marginalizados, Israel tem algumas das leis e políticas mais visionárias e progressistas do mundo. 0

\footnotetext{
${ }^{6}$ Dados do Israeli Central Bureau of Statistics (CBS), Statistical Abstract of Israel 2009, No. 60, Tabelas 2.2, $2.8,2.10$, contemplado na bibliografia.

7 Israel Democracy Institute, Auditing Israeli Democracy-2010, (Inglês), disponível em: http://www.idi.org.il/PublicationsCatalog/Documents/Book_7114/madad_2010_eng_abstract.pdfAcesso em 22 de Maio de 2014.

${ }^{8}$ Adalah Annual Report, disponível em: http://adalah.org/eng/category/52/Reports/1/0/0/. Acesso em 22 de Maio de 2014.

${ }_{9}^{9}$ Pesquisa encomendada pelo Instituto de Pesquisa Maagar Mochot: "Metade dos estudantes do ensino médio israelenses se opõem a igualdade de direitos para os árabes", Haaretz (versão em Inglês), 11 de Março de 2010.
} 
Knesset de Israel, por exemplo, aprovou uma consistente legislação anti-discriminatória e proteções legais para as mulheres e os deficientes físicos, no entanto, o mesmo não foi estendido para a minoria palestina. Como resultado, os palestinos, que também são membros de outros grupos marginalizados não recebem os benefícios de tais proteções. Mais de 30 Leis Principais discriminam, direta ou indiretamente, contra cidadãos palestinos de Israel, e a coalizão de governo atual tem proposto uma enxurrada de novas leis racistas e discriminatórias que estão em várias fases do processo legislativo.

Não obstante a todo esse quadro de leis discriminatórias, Israel ratificou todos os principais tratados de direitos humanos da ONU e é obrigado a estas convenções. Israel também é obrigado a seguir vários acordos UE-Israel que contêm obrigações sérias de direitos humanos. Desta forma, havendo o país assinado tais tratados internacionais vinculantes, tais como a Convenção internacional sobre a eliminação de todas as formas de discriminação racial (ICERD, do inglês International Convention on the Elimination of All Forms of Racial Discrimination), e seu governo se comprometido com as obrigações dos mesmos, apresentar-se-á alguns exemplos da disparidade legal existente entre a sua constituição e a legislação internacional a qual está submetido. Os princípios da igualdade e da não-discriminação são uma pedra angular do direito internacional dos direitos humanos. A fim de garantir o princípio da igualdade, instrumentos de direitos humanos apontam inúmeras razões pelas quais é proibida a discriminação, incluindo raça, sexo, religião, nacionalidade, língua e opinião política. Os Estados Partes dos instrumentos internacionais de direitos humanos são requeridos a promulgar estas disposições nas suas legislações nacionais. No entanto, em Israel o direito à igualdade e à liberdade de discriminação não é explicitamente consagrado na legislação como um direito constitucional, nem é protegido por lei.

\section{Cidadania e Identidade}

As leis mais importantes de imigração, incluindo a Lei do Retorno (1950) e a Lei de Cidadania (1952) privilegiam judeus e imigração judaica sobre os não-judeus. Aos 
judeus é concedido o direito de imigrar e tornar-se cidadãos israelenses, mesmo se estes não tiverem nenhuma conexão com Israel, enquanto 750 mil palestinos e seus descendentes expulsos em 1948 não têm esse direito. É quase impossível para os palestinos fora de Israel se tornarem cidadãos israelenses ${ }^{10}$.

Lei de Registro Populacional (1965) - Exige que todos os moradores de Israel registrem sua etnia (isto é, judeus, árabes, drusos) no Registro de População e obter um cartão de identidade divulgando esta informação. O Escritório do Alto Comissariado das Nações Unidas para os Direitos Humanos diz: "um sistema duplo de leis que discriminam entre judeus israelenses e palestinos com base no status construído de nacionalidade judaica. Esta aplicação prejudicial de direito é evidente em todos os processos do sistema jurídico, dos direitos à informação e julgamento justo à detenção e tratamento de prisão"11.

Unificação familiar (2003) - No âmbito da política de 2003 para "reagrupamento familiar", cônjuges não cidadãos e filhos de cidadãos israelenses árabes são proibidos de entrar em Israel (e viver com seu cônjuge / pai). Isto significa que se você é um palestino de fora de Israel, casado com uma israelense, você está impedido de viver com o seu cônjuge em Israel. Isto não se aplica a qualquer outra etnia exceto a árabe. Esta disposição tem sido regularmente prorrogada, mais recentemente, em janeiro de $2011^{12}$.

Servir as Forças Armadas - Judeus israelenses (com exceção de alguns judeus ortodoxos) tem que servir no exército de Israel quando completam 18 anos. A maioria dos palestinos é proibida de servir no exército. Muitos dos benefícios da sociedade são dados às pessoas que tenham anteriormente servido, como tratamento preferencial de habitação, educação e outros serviços ${ }^{13}$.

A Lei de Cidadania (2008) - Várias tentativas têm sido feitas nos últimos anos para tornar possível a revogação da cidadania israelense por parte do Estado, através de alegações de "deslealdade" para o Estado ou "quebra de confiança" (termos amplamente definidos). Todas essas tentativas têm indiretamente como alvo os direitos de cidadania dos cidadãos palestinos ${ }^{14}$.

\footnotetext{
10 Dados retirados do instituto Israel Law Resource Center - disponível em (http://www. israellawresourcecenter.org/) Acesso em: 14 de Junho de 2014.

11 Ibid.

12 Ibid.

13 Dados retirados do instituto Israel Law Resource Center - disponível em (http://www. israellawresourcecenter.org/) Acesso em: 14 de Junho de 2014. 


\section{E o que o direito internacional diz?}

Article 1. In this Convention, the term "racial discrimination" shall mean any distinction, exclusion, restriction or preference based on race, colour, descent, or national or ethnic origin which has the purpose or effect of nullifying or impairing the recognition, enjoyment or exercise, on an equal footing, of human rights and fundamental freedoms in the political, economic, social, cultural or any other field of public life.

Article 2. States Parties condemn racial discrimination and undertake to pursue by all appropriate means and without delay a policy of eliminating racial discrimination in all its forms and promoting understanding among all races, and, to this end: (a) Each State Party undertakes to engage in no act or practice of racial discrimination against persons, groups of persons or institutions and to en sure that all public authorities and public institutions, national and local, shall act in conformity with this obligation; (ICERD, International Convention on the Elimination of All Forms of Racial Discrimination, 1965)

\section{0 direito de Ir e Vir}

Os cidadãos palestinos de Israel não podem viajar para a maioria dos países árabes, que compartilham do mesmo quadro étnico-cultural e que estão a poucos quilômetros de distância (uma vez que Israel faz fronteira com quatro nações árabes). Existe a possibilidade de autorização de viagem do governo israelense mediante demanda formal no Ministério, entretanto, as aplicações por cidadãos palestinos para viajar para esses países são geralmente recusadas. São duas leis israelenses que condenam tal ato:

Seção 2o da Lei de Infiltração (1954) e Seção 5a da Lei de Emergência (1948) impor uma proibição abrangente sobre todas as pessoas com cidadania israelense ou residência, de viajar para países que são designados por Israel como "Estados inimigos", que incluem muitos países árabes e muçulmanos, independentemente do motivo da viagem, tais como visitas de familiares, viagens profissionais ou eventos culturais. (Adalah, 2011)

E o que o direito internacional diz?

Artigo $2^{2}$ - as pessoas pertencentes à minorias têm o direito de estabelecer e manter, sem qualquer discriminação, livre e pacificamente, contatos com outros membros de seu grupo e com pessoas pertencentes a outras minorias, assim como contatos através das fronteiras com os cidadãos de outros Estados a quem eles estão relacionados por laços nacionais ou étnicos, religiosos ou linguísticos. (Declaração da ONU sobre os Direitos das Pessoas Pertencentes a Minorias Étnicas, Religiosas e Linguísticas, 1992)

\section{Conclusão}


O presente trabalhou buscou brevemente fundamentar a lógica do Direito Internacional e explicar as dinâmicas políticas contemporâneas em que se insere o mesmo, corroborando-as através de um exemplo real. Por meio do contexto legal do Estado de Israel e suas várias contradições estruturais, comprova-se o que ainda acontece no cenário internacional: a constante dicotomia entre o que é julgado internamente e o desempenho do Estado externamente.

Sabe-se, e o presente trabalho não procurou negar, que o peso político para que os Estados se tornem parte de convenções internacionais existe, de fato. Contudo, analisando o exemplo israelense, conclui-se que muito pouco ainda é feito em termos de coesão e regulação a respeito do comportamento ilegítimo dos Estados, tornando o Direito Internacional mais uma vez fraco e insuficiente. Volta-se ao eterno dilema que enfrenta o Direito Internacional desde a origem: suas falhas são o que torna possível sua existência.

\section{Bibliografia}

ACCIOLY, Hildebrando. Tratado de Direito Internacional Público. São Paulo: Quartier Latin, 2009, $3 \mathrm{v}$.

ADALAH - The Legal Center for Arab Minority Right in Israel. Leis Discriminatórias. Disponível em: http://adalah.org; Acesso em: 22 de Maio de 2014.

FREITAS, Luna. O Direito Internacional E A Teoria Das Fontes: Reflexões Sobre As Normas Peremptórias Do Jus Cogens. Disponível em: http://www.ebah.com.br; Acesso em: 14 de Junho de 2014;

IMEU - Institute for Middle East Understanding. Disponível em: http://imeu.org/. Acesso em: 11 de Junho de 2014.

Israel Democracy Institute, Auditing Israeli Democracy-2010, (Inglês). Disponível em: http://www.idi.org.il;. Acesso em: 22 de Maio de 2014. 
Israel Law Resource Center. Disponível em: http://www.israellawresourcecenter.org/; Acesso em: 22 de Maio de 2014.

Israeli Central Bureau of Statistics (CBS), Statistical Abstract of Israel 2009, No. 60, Tabelas 2.2, 2.8, 2.10

KOSKENNIEMI, Martti. What is International Law for? in INTERNATIONAL LAW 57, 59 (Malcolm Evans, ed., 2d 2006).

MELLO, Celso D. de Albuquerque. Direito Internacional Público, Biblioteca Jurídica Freitas Bastos, 8a edição, 1986, 2 v.

OHCHR - Office of the High Commissioner for Human Rights. Disponível em: http://www.ohchr.org/EN. Acesso em: 30 de Maio de 2014.

REZEK, J.F. Direito Internacional Público - Curso Elementar, Ed. Saraiva, 8a edição, 2000.

UNITED NATIOS TREATY COLLECTION. Disponível em: https://treaties.un.org; Acesso em: 30 de Maio de 2014. 